\title{
Research of The Grid-connected Simulation Model Improvement of Double-fed Induction Generator
}

\author{
Bai Qinyu ${ }^{1, a}$, Xu Jun ${ }^{2, b}$, Zhang Yonggang ${ }^{3}$, Chen $\mathrm{Yu}^{4}$ and Wang Youyin ${ }^{5}$ \\ ${ }^{1}$ Electric Power Research Institute of State Grid Liaoning Electric Power Co.,Ltd. China. \\ ${ }^{2}$ State Grid Huangshi Electric Power Supply Company \\ ${ }^{3}$ State Grid Tongliao Power Supply Company \\ ${ }^{4}$ China Satellite Tracking \& Control Department, Yuan Wang 3 \\ ${ }^{5}$ State Grid Liaoning Economic Research Institute \\ aE-mail: winterinse@163.com, bemail: 3186950565@qq.com
}

\begin{abstract}
Keywords: DFIG model, output characteristic of wind turbine generator, data fitting, simulation accuracy

Abstract. In this paper, aimed at reducing deviation of the output characteristic between DFIG model and operating wind turbine generator. A method using measured data for modifying the model of DFIG is provided. Firstly, the data fitting method is used to get the mathematical model of the operating turbine. Secondly, the model is studied to improve its control strategy. At last, an example is given in PSCAD and showed that the modified model truthfully reflects the output characteristics of the operating wind turbine generator which improved the integration simulation accuracy of DFIG.
\end{abstract}

\section{Introduction}

Doubly fed wind generator (DFIG) has become the mainstream type of wind turbine ${ }^{[1]}$. In the simulation calculation of the grid connected operation of doubly fed wind generator and its influence, it is important to establish a model which can accurately reflect the actual output characteristic of doubly fed wind power generator ${ }^{[2]}$.

There has been a plenty of studies of the numerical simulation model of doubly fed wind generator and its control system at home and abroad ${ }^{[3-5]}$. In this paper, the Lagrange interpolation method is used to process the measured data of DFIG for gaining the characteristic curve of output power. Then, the related function between active and reactive power is improved according to the characteristic curve. The node voltage amplitude of load switching has more fluctuation in recovery process by calculating the short-circuit fault and load switching with the 50MVA double-fed wind farm simulation model. And the short-circuit fault node has more variations in angle and frequency. The simulation model of DFIG has a profound influence on transient calculation results.

\section{Curve Fitting Method Of The Measured Characteristic}

The output power of the wind turbine is mainly achieved by measuring the voltage and current of the connecting node. The analog signals of voltage and current are sampled and converted to a series of discrete series after a certain frequency. A series of discrete values of voltage $u(n)$ and current $i(n)$ are sampled by $N$ times in a period, then the effective value of voltage $U_{\text {rms }}$, current $I_{\text {rms }}$, and active power $P$ are obtained by Eq. 1 .

$$
U_{r m s}=\sqrt{\frac{1}{N} \sum_{n=0}^{N-1} u^{2}(n)}, I_{r m s}=\sqrt{\frac{1}{N} \sum_{n=0}^{N-1} i^{2}(n)}, P=\frac{1}{N} \sum_{n=0}^{N-1} u(n) i(n)
$$

The apparent power $\mathrm{S}$ and power factor $\cos \varphi \operatorname{can}$ be obtained through the effective value of voltage, current and active power which can be used for calculating the active and reactive power. 


$$
S=U_{r m s} \times I_{r m s}, \cos \varphi=\frac{P}{S}
$$

The relation equation between the measured active and reactive power is obtained by fitting the data. In this paper, the Lagrange interpolation method is used for data fitting. The main method is to obtain the function values of a series of points $y_{\mathrm{i}}=f\left(x_{\mathrm{i}}\right)(\mathrm{i}=0,1,2 \ldots, \mathrm{n})$ in a certain range by measurement or experiment and establish an equation $p(x)$, which have the same function characteristic of $f(x)$ and also be easy to calculate with $p\left(x_{\mathrm{i}}\right)=f\left(x_{\mathrm{i}}\right),(\mathrm{i}=0,1,2 \ldots \mathrm{n})$. The functional curve between reactive power and active power can be obtained according to the data processing method which can be used for obtaining the output characteristic function of them. The applying of Lagrange interpolation method can be seen in paper ${ }^{[6]}$.

\section{The Improved Model of DFIG System}

The Macroscopically Model. Double fed wind power generation system is composed with the following modules: wind turbine, doubly fed wind power generator, grid side converter, machine side converter, converter control system and the pitch angle control system. Schematic diagram of the structure is shown in Fig.1.

Mathematical Model of Network Side Converter. The grid side converter adopts three-phase voltage PWM rectifier with the main circuit topology shown in Fig.2.

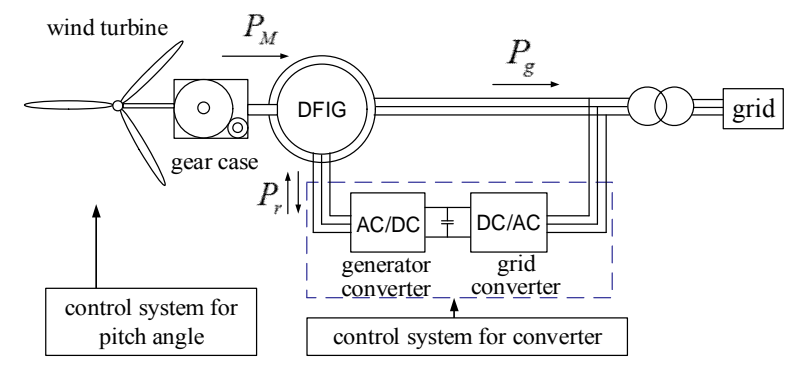

Fig.1 Doubly fed wind power system

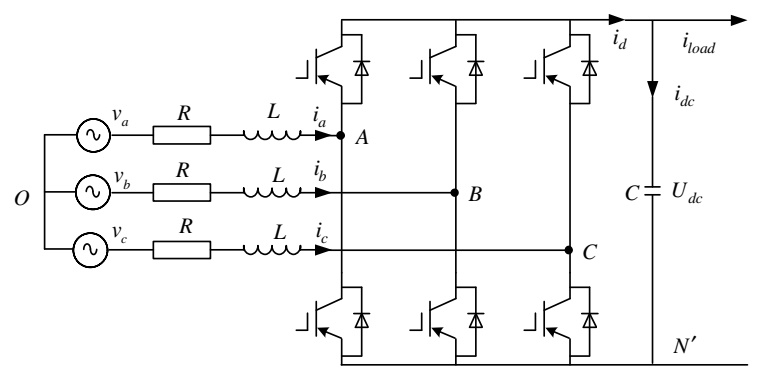

Fig.2 Grid side PWM converter topology structure

The mathematical model in the d-q coordinates of the grid side PWM converter can be obtained by coordinate changes which shown in Eq. 2.

$$
L \frac{d i_{d}}{d t}=-R i_{d}+\omega_{e} L i_{q}-S_{d} u_{d c}+v_{d}, L \frac{d i_{q}}{d t}=-R i_{q}-\omega_{e} L i_{d}-S_{q} u_{d c}+v_{q}, C \frac{d u_{d c}}{d t}=\frac{3}{2} S_{d} i_{d}+\frac{3}{2} S_{q} i_{q}-i_{\text {load }}
$$

The $i_{\mathrm{d}}$ and $i_{\mathrm{q}}$ are the components of grid side converter input three-phase current in $d q$ axis which shown in Eq. 2. The $i_{\mathrm{dc}}$ is the output current on DC bus of the grid side converter. The $i_{\text {load }}$ is the current of load at DC side of the converter in grid side. The $v_{\mathrm{d}}$ and $v_{\mathrm{q}}$ are the components of the grid three-phase voltage in $d q$ axis. The $u_{\mathrm{dc}}$ is the voltage of DC bus. The $L$ is the equivalent reactance of transmission line, and the $R$ is the line equivalent resistance. The $\omega_{\varepsilon}$ is the rotation angle speed of power grid voltage vector. The $S_{\mathrm{d}}$ and $S_{\mathrm{q}}(\mathrm{i}=1,2,3)$ on $d q$ axis are the switching functions of the phase of $I$ with the value of them defined by the conducting state of bridge arm. It equals 1 when upper conduit is conducting, and it equals 0 when lower conduit is conducting.

Control Strategy of Grid Side Converter of Doubly Fed Wind Power Generator. The voltage vector direction is orientated on the coordinate axes $d$ of synchronous rotating $d q$ coordinate system which achieved by making $v_{\mathrm{d}}=u_{\mathrm{s}}$ and $v_{\mathrm{q}}=0$. The value of $v_{\mathrm{d}}$ is constant, and the active power and reactive power are respectively proportional to $i_{\mathrm{d}}$ and $i_{\mathrm{q}}$ because of the constant of the voltage in grid side.

$$
\left\{\begin{array}{l}
P=v_{d} i_{d}+v_{q} i_{q}=v_{d} i_{d} \\
Q=v_{q} i_{d}-v_{d} i_{q}=-v_{d} i_{q}
\end{array},\left\{\begin{array}{l}
v_{d}=v_{d}^{\prime}-\omega_{e} L i_{q}+v_{d 1} \\
v_{q}=0=v_{q}^{\prime}-\omega_{e} L i_{d}+v_{q 1}
\end{array}, v_{d}^{\prime}=R i_{d}+\frac{L i_{d}}{d t}, v_{q}^{\prime}=R i_{q}+\frac{L i_{q}}{d t}, v_{d 1}=S_{d} u_{d c}, v_{q 1}=S_{q} u_{d c}\right.\right.
$$


The objective of the improved grid side converter control is to ensure the active and reactive power output characteristics of DFIG is conformed to reality. As shown in Fig.3, the control strategy of grid side converter is an instantaneous power closed loop control of $P$ and $Q$. The $P_{\text {ref }}$ command is obtained by the DC bus voltage through PI regulator. The $Q_{\text {ref }}$ command can be calculated by measuring and functional fitting the data of the instantaneous active power $P$ in grid. The PWM wave command of voltage in grid voltage source converter is shown in Eq. 4.

$$
v^{*}{ }_{d}=-\left(K_{P P}+\frac{K_{P I}}{s}\right)\left(P_{r e f}-P\right)+\omega_{e} L i_{q}+u_{s}, v_{q}^{*}=-\left(K_{Q P}+\frac{K_{Q I}}{s}\right)\left(Q_{r e f}-Q\right)-\omega_{e} L_{s} i_{d}
$$

The $v_{\mathrm{d}}{ }^{*}$ and $v_{\mathrm{q}}{ }^{*}$ are the modulation wave voltage command values in power supply side converter.

\section{Simulation Analysis}

Simulation and Calculation of Double Fed Wind Power Output Characteristics. A 2MW rated capacity double fed wind turbine model is built in PSCAD with improved control structure shown in Fig.3. The control model of active and reactive power is determined by functional fitting the measured data which shown in Fig.4. The main parameters are showed in Table 1.

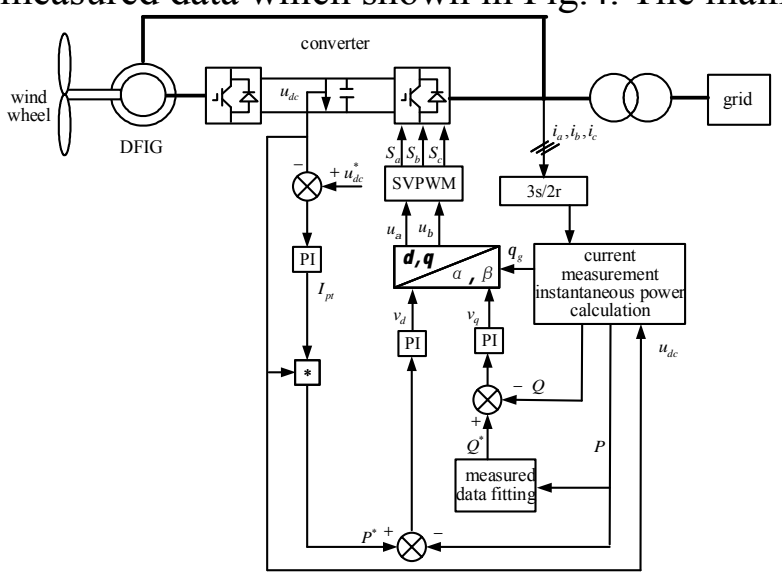

Fig.3 Network side converter improved control

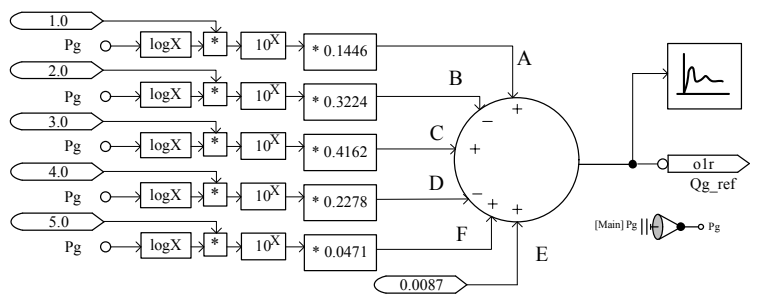

Fig.4 The model of active and reactive power structure

Determined by the measured power output curve, the improved model is calibrated by using single machine infinite bus system. Wind speed is slowly adjusted from $5 \mathrm{~m} / \mathrm{s}$ to $15 \mathrm{~m} / \mathrm{s}$ with steady-state power value collected of model connected point. The Fig. 5 shows data curve of DFIG output power obtained by functional fitting. It can be clearly seen that the changes of active power output in the existing model is a significant difference with the output power of measured data. Fig.5(c) shows the power curve of the double fed induction generator improved model which consistent with the changing trend of measured data curve in Fig.5(a).

Table 1 Main parameters of 2MW double fed wind turbine simulation system

\begin{tabular}{cccccccc}
\hline $\begin{array}{c}\text { Fan } \\
\text { parameters }\end{array}$ & $\begin{array}{c}\text { Rated } \\
\text { power }\end{array}$ & $\begin{array}{c}\text { Rated } \\
\text { speed }\end{array}$ & Frequency & $\begin{array}{c}\text { Power } \\
\text { factor }\end{array}$ & $\begin{array}{c}\text { Rated } \\
\text { voltage of } \\
\text { stator }\end{array}$ & $\begin{array}{c}\text { Stator } \\
\text { resistance }\end{array}$ & $\begin{array}{c}\text { Stator } \\
\text { reactance }\end{array}$ \\
\hline Value & $2[\mathrm{MW}]$ & $1800[\mathrm{rpm}]$ & $50[\mathrm{~Hz}]$ & \pm 0.95 & $690[\mathrm{~V}]$ & $0.0018[\Omega]$ & $0.0027[\mathrm{H}]$
\end{tabular}

Some data from Fig.5(a) and Fig.5(c) are taken for error analysis. The output error of reactive power could be calculated by $e=(Q 3-Q 1) / Q 1 * 100 \%$ when active output powers are same. By calculating, the error range is less than $\pm 1 \%$, which proves that the model in this paper is accurate and effective. 
Transient Calculation of Local Network with Doubly Fed Wind Farm. A simulation system with 50MVA double fed wind farm which used a large capacity equivalent model is built in PSCAD/EMTDC as shown in Fig.6.

WG is the equivalent model of the wind farm with $13.8 \mathrm{KV}$ output voltage and two 20MVA capacity booster transformers for connecting to grid. The $\mathrm{S}$ is the equivalent grid. The G3, G2 is 60MW capacity thermal power plants. Load 1, Load 2, and Load 3 are respectively loads with capacities of (42+j17)MVA, $(33+\mathrm{j} 12) \mathrm{MVA}$, and $(30+\mathrm{j} 10) \mathrm{MVA}$.



(a) Practical operation



(b) Improved pre model



(c) Improved model

Fig.5 Characteristic curve of power output of DFIG

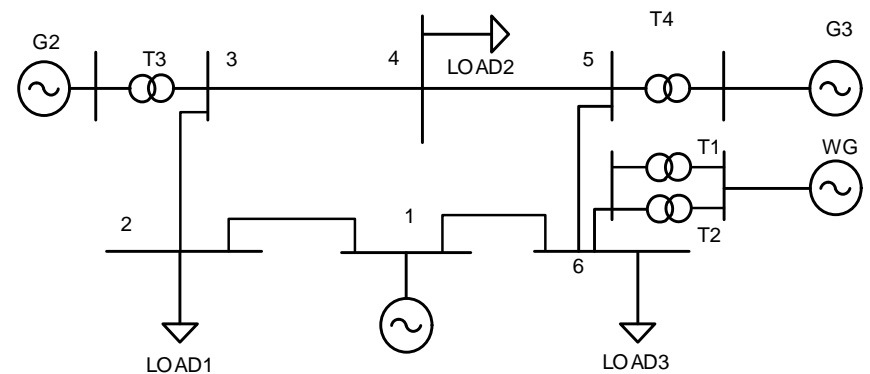

Fig. 6 Simulation system of doubly fed wind farm

\section{operating with short circuit}

The operating fault is designed as single phase to ground fault which occurs in middle point of $230 \mathrm{KV}$ No. 6 bus at $1 \mathrm{~s}$ point time and removes after $0.05 \mathrm{~s}$ maintaining. The graph curves of voltage, frequency, and power angle in No.6 bus are obtained by simulation operating as shown in Fig. 7.

As shown in Fig.7, compared with existing model, the improved model has greater amplitudes of voltage and frequency, faster recovery, and lesser amplitude of power angle during the fault recovery process.

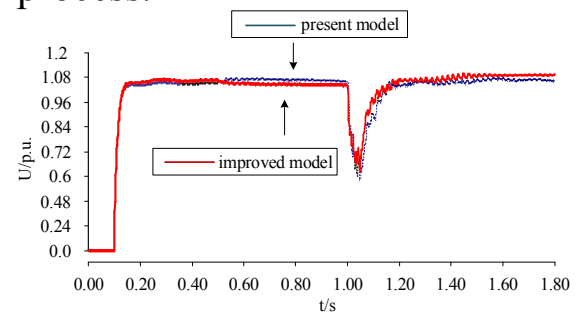

(a) The voltages

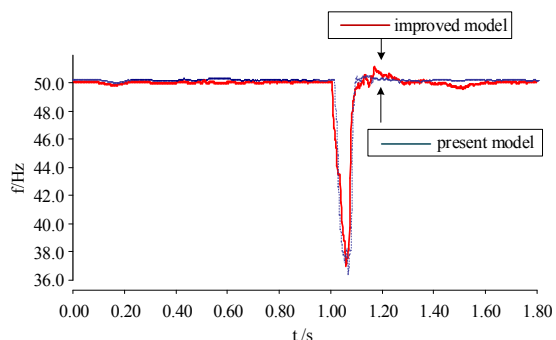

(b) The frequencies

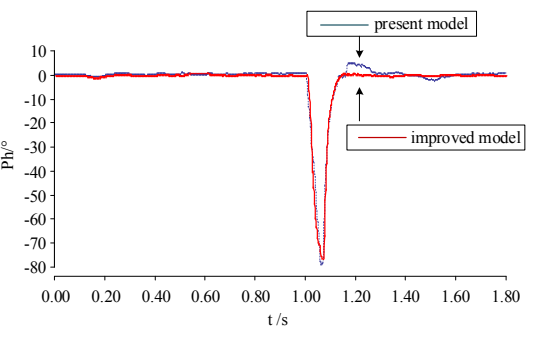

(c) The power angles

Fig. 7 The value curves of voltage, frequency, and power angle in No.6 bus with short circuit operating with load switching

The No.3 Load is cut off at $1 \mathrm{~s}$ time point and reconnected after $0.05 \mathrm{~s}$ maintaining. The graph curves of voltage, frequency, and power angle in No.6 bus are obtained by simulation operating as shown in Fig.8.

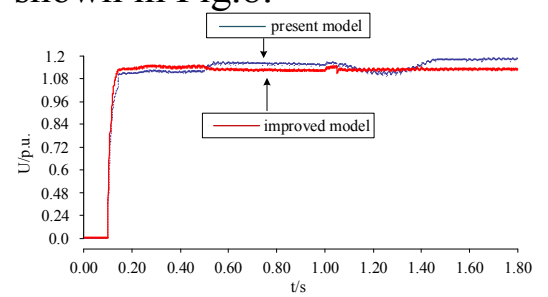

(a) The voltages

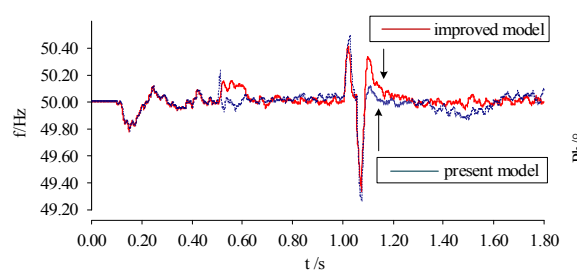

(b) The frequencies

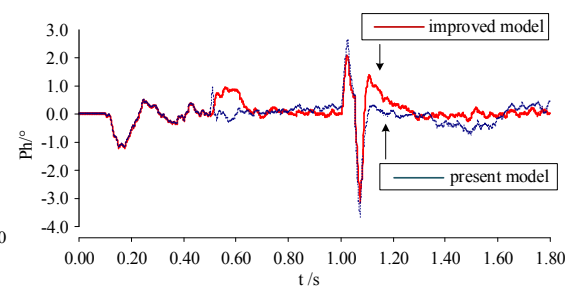

(c) The power angles

Fig.8 The value curves of voltage, frequency, and power angle in No.6 bus with load switching 
As shown in Fig.8, compared with existing model, the improved model has shorter amplitude of voltage, shorter concussion time, greater amplitudes of frequency which ranged from $50.3 \mathrm{~Hz}$ maximum to $49.7 \mathrm{~Hz}$ minimum, and greater power angle which ranged from $2.3^{\circ}$ maximum to $-3.3^{\circ}$ minimum.

\section{Conclusions}

This paper presents a method for improving the model of DFIG. The method is based on the DFIG output power curve which obtained by functional fitting the measured data of DFIG integration connecting point. Some conclusions are obtained with operation simulation of a DFIG connecting system model as shown following:

1. The improved model can effectively reflect the output characteristics of the wind turbine in actual operation as the measured data have less than $\pm 1 \%$ deviation by using the improved model.

2. The calculation results of transient operations like short circuit fault and load switching could be obviously influenced by the accuracy of DFIG simulation model output characteristics

\section{References}

[1] L. I. Sheng, N. Wang, Z, Chang. Nonlinear control of doubly-fed wind generator power decoupling: Computer engineering \& applications Vol. 13 (2015), p. 164-169

[2] Z. D. Zhang, H. Z. Ma, W. J. Shi, J. I. Chen, T. T. Chen. Study on extraction method of stator winding fault characteristics of doubly-fed wind generator: Micromotors Vol. 24 (2014), p. 563-568

[3] G. Wei, L. Xue, Y. Li. A grid-connected double-fed wind generator control design by using an adaptive sliding mode excitation approach: Icic express Letters Part B Applications An International Journal of Research \& Surveys Vol. 5 (2014), p. 1223-1230

[4] Z. Y. Li, Q. H. Liu, X. M. Wang. The performance analysis and comparison of the simplified method of the doubly-fed wind generator model: Applied Mechanics \& Materials Vol. 411 (2013), p. 1831-1835

[5] S. Y. Ding, Z. Q. Sun, J. Nan. Numerical simulation of rheological properties inside large doubly-fed wind generator: Electric Machines \& Control Vol. 3 (2011), p. 257-264

[6] Z. Li, Q. Liu, X. Wang. Full order model of doubly-fed wind generator and simplified methods: Telkomnika Indonesian Journal of Electrical Engineering Vol. 3 (2014), p. 2327-2336 